\title{
Optimization of the human colorectal carcinoma antigen GA733-2 production in tobacco plants
}

\author{
Se Hee Park ${ }^{1}$ Kon-Young $\mathrm{Ji}^{2} \cdot$ Hyun Min Kim ${ }^{1}$ - Sang Hoon Ma ${ }^{1}$. Seo Young Park ${ }^{1}$. Ju Hui Do ${ }^{1}$ - Doo-Byoung $\mathrm{Oh}^{3,4}$. \\ Hyung Sik Kang ${ }^{1}$. Jae Sung Shim ${ }^{1}$. Young Hee Joung ${ }^{1}$ (i)
}

Received: 29 September 2020 / Revised: 3 December 2020 / Accepted: 8 December 2020 / Published online: 23 January 2021

(c) Korean Society for Plant Biotechnology 2021

\begin{abstract}
The colorectal carcinoma-associated protein GA733-2 is one of the representative candidate protein for the development of plant-derived colorectal cancer vaccine. Despite of its significant importance for colorectal vaccine development, low efficiency of GA733-2 production limits its wide applications. To improve productivity of GA733-2 in plants, we here tested multiple factors that affect expression of recombinant GA733-2 (rGA733-2) and rGA733 fused to fragment crystallizable (Fc) domain (rGA733-Fc) protein. The rGA733-2 and rGA733-Fc proteins were highly expressed when the pBINPLUS vector system was used for transient expression in tobacco plants. In addition, the length of interval between $r G A 733-2$ and left border of T-DNA affected the expression of rGA733 protein. Transient expression analysis using various combinations of Agrobacterium tumefaciens strains (C58C1, LBA4404, and GV3101) and tobacco species (Nicotiana tabacum cv. Xanthi $\mathrm{nc}$ and Nicotiana benthamiana) revealed that higher accumulation of rGA733-2 and rGA733-Fc proteins were obtained by combination of A. tumefaciens LBA4404 and Nicotiana benthamiana. Transgenic plants generated by introduction of the rGA733-2 and rGA733-Fc expression cassettes also significantly accumulated corresponding recombinant proteins. Bioactivity and stability of the plant-derived rGA733 and rGA733-Fc were evaluated by further in vitro assay, western blot and $\mathrm{N}$-glycosylation analysis. Collectively, we here suggest the optimal condition for efficient production of functional rGA733-2 protein in tobacco system.
\end{abstract}

Keywords Colorectal cancer · GA733-2 · Plant-derived therapeutic protein · Transgenic plants · Transient expression

Jae Sung Shim

jsshim@chonnam.ac.kr

$\triangle$ Young Hee Joung

yhjoung@chonnam.ac.kr

Se Hee Park

shpark860@hanmail.net

Kon-Young Ji

jky8387@kiom.re.kr

Hyun Min Kim

hmkimbol@gmail.com

Sang Hoon Ma

kingmasalo@naver.com

Seo Young Park

syprk21@gmail.com

Ju Hui Do

juhuido20@gmail.com
Doo-Byoung Oh

dboh@kribb.re.kr

Hyung Sik Kang

kanghs@jnu.ac.kr

1 School of Biological Sciences and Technology, Chonnam National University, Gwangju 61186, Korea

2 Herbal Medicine Research Division, Korea Institute of Oriental Medicine, Daejeon 34054, Korea

3 Synthetic Biology and Bioengineering Research Center, Korea Research Institute of Bioscience and Biotechnology (KRIBB), Daejeon 34141, Korea

4 Department of Biosystems and Bioengineering, University of Science and Technology (UST), Daejeon 34113, Korea 


\section{Introduction}

Colorectal cancer is one of the most common malignancy associated death worldwide. Colorectal cancer is defined as an abnormal growth of a polyp on the inner lining of the colon and rectum that can become cancerous and spread into other parts of the body (Koido 2013; Sarvizadeh et al. 2019). Optimization of surgical resection dramatically improves 5- to 10-year survival rates of patients with localized disease, but approximately $25 \%$ of them has a possibility to have a relapse due to the presence of metastasis (Tauriello et al. 2017; Temraz et al. 2014). Thus, it is important to develop alternative treatments that can improve survival rate of colorectal cancer patients. One of such approaches is the development of cancer vaccine (Abakushina et al. 2019; Bracci et al. 2020; Wong-Arce et al. 2017).

Vaccines help stimulation of the immune response against particular diseases (Francis 2018; Mason 2016). There are several different systems that can be used for the production of vaccines (Shanmugaraj et al. 2020). Bacterial system has several advantages as a tool for recombinant protein production such as easy manipulation, high expression level, and ease of scale up (Rosales-Mendoza et al. 2016, Shanmugaraj et al. 2020). However, some recombinant proteins produced by bacterial system failed to retain its biological activity due to improper folding or lack of post-translational modification (Tokmakov et al. 2012). Compare to bacterial system, mammalian cell system allows proper folding and authentic post-translational modification of recombinant protein (Lomonossoff and D'Aoust 2016, Shanmugaraj et al. 2020). Based on the advantages, mammalian cell system have contributed to produce many commercially available vaccines (Francis 2018; Rajaram et al. 2020; Zost et al. 2017). Despite of the advantages, high production cost and possible contamination of human pathogens have been regarded as hurdles for application of mammalian cell system for vaccine production (Schillberg et al. 2019). As a alternatives of mammalian system, plant systems have been in spotlight for the production of vaccine candidates (Lomonossoff and D'Aoust 2016, Rybicki 2009, Shanmugaraj et al. 2020, Takeyama et al. 2015). The key advantages of plant system for production of pharmacological recombinant proteins are low production cost, easy cultivation, rapid mass production, inherent safety from human pathogens (Lomonossoff and D'Aoust 2016; Rybicki 2009). Moreover, the use of plant system to produce vaccine candidates allows proper post-translational modifications which are crucial for achieving their desired biological functions. (Blokhina et al. 2020; Brodzik et al. 2008; Daniell et al. 2009; Tusé et al. 2020). For these reasons, there are many attempts testing the feasibility of plants system for production of recombinant proteins (Joung et al. 2016, Shanmugaraj et al. 2020, Tusé et al. 2020). For example, "Elelyso", a medicine for Gaucher's disease has been registered as the first plant-based pharmacological recombinant protein (Fox 2012).

Among the plant systems, tobacco system has been extensively used for the production of pharmacological proteins due to its several advantages such as relatively easy transformation, robust protein expression capacity, and short life cycle (Daniell et al. 2001; Grosse-Holz et al. 2018). Golovkin et al. reported the production of the recombinant vaccinia virus B5 antigenic domain (pB5) as a component of vaccine against smallpox in tobacco (Golovkin et al. 2007). Application of plant-derived pB5 conferred protection from lethal dose of vaccinia virus (Golovkin et al. 2007). Similarly, domain III of the dengue 2 envelope protein expressed in tobacco plants induced the production of the anti-dengue virus antibody in mice (Saejung et al. 2007). In addition to virus vaccines, many cancer vaccines have been expressed in tobacco system (Lee and Ko 2017; McCormick 2011). Personalized recombinant vaccines against follicular B cell lymphoma were generated in tobacco system. A phase I safety and immunogenicity clinical trial of the vaccines revealed that almost half of the patients (47\%) successfully developed antigen-specific responses (McCormick et al. 2008). The transmembrane human epithelial mucin MUC1 that is over-presented in breast cancer cells was expressed in tobacco system. The plant-derived MUC1 tandem repeat fused to the Escherichia coli enterotoxin B subunit induced production of anti-MCU1 antibodies (Pinkhasov et al. 2011).

For successful development of cancer vaccines, it is necessary to identify and produce tumor-specific antigens that can induce immune response against cancer cells. GA733 proteins have been regarded as potential target antigens that can be used for the production of colorectal cancer vaccines (Fu et al. 2018; Lu et al. 2012; Mamaloudis et al. 2015; Park et al. 2015a). GA733 protein belongs to the group of calcium independent cell adhesion molecules (CAM), which are highly accumulated on the cell surface of colorectal carcinomas (Mamaloudis et al. 2015). Expression of GA733 or its murine homologue in tumor cells inhibited growth of colorectal cancer cells (Armstrong and Eck 2003; Basak et al. 1998; Li et al. 1997). In addition, GA733-2, a member of GA733 family, produced in tobacco or swiss chard also successfully induced immune responses and inhibited tumor growth in mice (Brodzik et al. 2006, 2008; Verch et al. 2004). However, lower expression level of GA733-2 protein was regarded as a constraint for further applications (Lim et al. 2014; Park et al. 2015b). Thus, optimization of recombinant GA733-2 (rGA733-2) protein expression in plant systems is prerequisite for efficient production of GA733 and its application as a cancer vaccine. In this study, we 
tested several potential factors that affect expression level of rGA733 and rGA733 fused to Fc domain (rGA733-Fc) recombinant protein in tobacco plants. In addition, we generated transgenic tobacco plants that produce rGA733 and rGA733-Fc, respectively, for stable production of the antigens. Finally, the stability and functionality of the recombinant proteins were confirmed by western blot, ELISA, glycosylation pattern, and in vitro analysis.

\section{Materials and methods}

\section{Plant expression vector construction}

Various plant expression vectors were generated for the expression of the rGA733-2 and the rGA733-Fc protein as described below. The DNA sequence encoding truncated human colorectal carcinoma antigen GA733-2 (aa17aa266) (Park et al. 2015a; Szala et al. 1990) and GA733$\mathrm{Fc}$ recombinant protein sequence ( $\mathrm{Fc}$ fragment of human IgG1 (Val97-Gly328, GenBank accession no. AY172957) were amplified with GA733-Fsal (5'-ACGTCGACATGG ATACGGCG- ${ }^{\prime}$ ) and GA733-Rsac (5'-TGAGCTCTCACA CGTGGTGGTG-3') primers. The amplified GA733-2 and GA733-Fc fragments were introduced into the pBI121 vector carrying the $35 S$ promoter, the $5^{\prime}$ UTR sequence from the tobacco etch virus and a segment of DNA sequence encoding 30-aa length plant ER signal peptide (MATQRRANPSSLHLITVFSLLAAVVSAEVD, ER signal peptide from Nicotiana plumbaginifolia) through SalI and SacI restriction enzyme sites. The final constructs were named as pBI121-GA733 and pBI121-GA733-Fc, respectively. GA733-2 and GA733-Fc were amplified from pBI121GA733 and pBI121-GA733-Fc expression vector with GA733-Fsal and KDEL-Rsnab (5'-TGTACGTATCAGAGT TCATCTTT- $3^{\prime}$ ) primers, and cloned into pBINPLUS vector containing $35 S$ promoter, the $5^{\prime}$ UTR sequence from the tobacco etch virus and the ER signal peptide through SalI and SnaBI sites. The final constructs were named as pBINPLUS-GA733 and pBINPLUS-GA733-Fc, respectively. To generate pPZP-200-GA733, the GA733-2 expression cassette ( $p 35 S: U T R-S P-G A 733-F c-t 35 S$ ) was isolated by digestion with HindIII from the pBINPLUS-GA733 plant expression vector, and cloned into the pPZP-200 vectors through a HindIII enzyme site. The pPZP-Bar-GA733 expression vector was constructed by introducing the GA733-2 expression cassettes ( $p 35 S: U T R-S P-G A 733-t 35 S$ ) into the pPZPBar expression vector through a HindIII enzyme site. The pBINPLUS vector containing the $5^{\prime}$ UTR from the tobacco etch virus and a sequence encoding a plant ER signal peptide were obtained from Dr. Kisung Ko of Chung-Ang University. The pPZP-200 and pPZP-Bar vectors were obtained from Dr. Ju-Kon Kim of Seoul National University.
To determine the relationship between rGA733-2 expression and structure of T-DNA, serial truncates of Bacillus subtilis NADPH-cytochrome P450 reductase 102A2V4 gene (GenBank accession no. FJ899088) (200, 400, 600, $800,1000,1200,1400,1600,1800$, and $2000 \mathrm{bps}$ in length) were amplified with following primers; 2000-F: $5^{\prime}$-TCC GGCCGG AACGGTTCGAG-3', 200-R: 5'-ATAAGGTTT GTTTGATA-3', 400-R: 5'-ATCGCCTTC TGCGGTGC-3', 600-R: 5'-ATGACGCCCTCAAGCTC-3', 800-R: 5'-ATC CGAATGCTTTGATG-3', 1,000-R: 5'-ATGATATTCAAC ATCCG-3', 1,200-R: 5'-ATTGTGGCTGCTTCCTG-3', 1,400-R: 5'-ATCTCGGTTTTAACGGA-3', 1,600-R: 5' -ATGGTCTTCCGGAAGCT-3', 1,800-R: 5'-ATGTGG ACAGTGACGAT-3', 2,000-R: 5'-CCTGCAGATGTCTCA GCCAG- ${ }^{\prime}$. Each DNA fragments were sub-cloned into the pGEM-T Easy Vector (Promega, USA). The fragments confirmed by sequence analysis were introduced into the pPZP200 vector through an EcoRI restriction enzyme site.

\section{Transient expression in tobacco leaves}

Six- to 8-week-old N. tabacum cv. Xanthi nc and N. benthamiana plants grown in a growth room $(16 \mathrm{~h}$-light/ $8 \mathrm{~h}$-dark cycle, $24{ }^{\circ} \mathrm{C}$ ) were used for transient expression of rGA733-2 and rGA733-Fc proteins. The Agrobacterium tumefaciens (A. tumefaciens) C58C1, LBA4404 and GV3101 strains were incubated in YEP medium $(10 \mathrm{~g} / \mathrm{L}$ yeast extract, $10 \mathrm{~g} / \mathrm{L}$ peptone, and $5 \mathrm{~g} / \mathrm{L} \mathrm{NaCl}, \mathrm{pH}$ 7.2) for 2 days. The bacterial cells were harvested by centrifugation at $13,000 \mathrm{rpm}$ for $20 \mathrm{~min}$, and the harvested cells were resuspended in $10 \mathrm{mM}$ $\mathrm{MgCl}_{2}$ (Final $\mathrm{OD}_{600}=0.9$ ) containing $200 \mu \mathrm{M}$ acetosyringone ( $\mathrm{pH}$ 5.6). The tobacco intact leaves were infiltrated with the bacterial suspension using a 1-ml needless plastic syringe. The infiltrated tobacco leaves were harvested at the indicated time points after infiltration and immediately frozen in liquid nitrogen for further analysis.

\section{Agrobacterium-mediated transformation of tobacco plants}

Transgenic tobacco plants were generated through the agrobacterium-mediated transformation method as previously described (Horsch et al. 1989). Fully expanded unstressed leaves from a sterile cultured Nicotiana tabacum cv.Xanthi plant were cut into squares with diameter of $0.5-1.0 \mathrm{~cm}$, and the leaf disks were incubated with LBA4404 agrobacterium harboring a plant expression vector for $10 \mathrm{~min}$. After the inoculation, the disks were placed with their adaxial surfaces facing downwards on co-cultivation medium [3\% sucrose, $4.4 \mathrm{~g} / \mathrm{L}$ MS salt (Duchefa, Netherlands), $2 \mathrm{mg} / \mathrm{L}$ 2,4-D (Duchefa, Netherlands), and $200 \mu \mathrm{M}$ acetosyringone (MBcell, Korea), $\mathrm{pH}$ 5.8]. After 2 days of co-cultivation, the disks were 
transferred into shoot induction medium [3\% sucrose, $4.4 \mathrm{~g} / \mathrm{L}$ MS salt, $50 \mathrm{mg} / \mathrm{L}$ kanamycin (Biosesang, Korea), $0.01 \mathrm{mg} / \mathrm{L}$ NAA (Duchefa, Netherlands), $0.1 \mathrm{mg} / \mathrm{L}$ GA3 (Duchefa, Netherlands), $1 \mathrm{mg} / \mathrm{L}$ zeatin (Duchefa, Netherlands), and $250 \mathrm{mg} / \mathrm{L}$ cefotaxime (Biosesang, Korea), $\mathrm{pH}$ 5.8]; the explants were transferred into fresh shoot induction medium every 2-3 weeks. The regenerated shoots were transferred to root induction medium (3\% sucrose, $4.4 \mathrm{~g} / \mathrm{L}$ MS salt, $50 \mathrm{mg} / \mathrm{L}$ kanamycin, and $300 \mathrm{mg} / \mathrm{L}$ cefotaxime, $\mathrm{pH}$ 5.8). The regenerated plantlets were transferred to soils.

\section{Protein extraction and western blot analysis}

Total soluble proteins were isolated from tobacco leaves. The harvested tobacco leaves were homogenized using a TissueLyser II (Qiagen, USA) with one volume of Bradley buffer (Bradley and Zaitlin 1971) at $30 \mathrm{~Hz}$ for $5 \mathrm{~min}$. The crude extracts were centrifuged at $13,000 \mathrm{rpm}$ for $30 \mathrm{~min}$ at $4{ }^{\circ} \mathrm{C}$, and the supernatants were separated on $10 \%$ or $12 \%$ SDS polyacrylamide gels and transferred to a polyvinylidene fluoride membrane (GE Healthcare, USA). The membrane was incubated with blocking buffer [1\% bovine serum albumin (BSA) and $5 \%$ skim milk] at $25{ }^{\circ} \mathrm{C}$ for $3 \mathrm{~h}$ and then washed with TBST $(150 \mathrm{mM} \mathrm{NaCl}, 2.5 \mathrm{mM} \mathrm{KCl}, 25 \mathrm{mM}$ Tris base, and $0.1 \%$ Tween-20). Rabbit rGA733-2 specific antibody was used as a primary antibody (1:5000 dilution) (Park et al. 2015a) and HRP-conjugated goat anti-rabbit IgG was used as a secondary antibody (1:5000 dilution, Thermo Scientific, USA). The proteins were visualized using an ECL system (Millipore, USA) and a LAS-3000 luminescent image analyzer (Fujifilm, Japan).

\section{Enzyme-linked immunosorbent assay (ELISA)}

The soluble fraction of crude extracts were diluted in $100 \mathrm{mM}$ carbonate-bicarbonate coating buffer $(28.6 \mathrm{mM}$ $\mathrm{Na}_{2} \mathrm{CO}_{3}$ and $71.4 \mathrm{mM} \mathrm{NaHCO} 3, \mathrm{pH}$ 9.6) to a final concentration of $10 \mu \mathrm{g} / \mathrm{ml}$, and $1 \mu \mathrm{g}$ of soluble protein was used for ELISA analysis. All process was performed in a 96-well immunoassay plate. The samples were blocked with $200 \mu \mathrm{l}$ of $5 \%$ skim milk in PBS buffer $(16.34 \mathrm{mM} \mathrm{Na} 2 \mathrm{HPO} 4$, $2.68 \mathrm{mM} \mathrm{KCl}, 0.94 \mathrm{mM}$ K3PO4, $136.9 \mathrm{mM} \mathrm{NaCl}, \mathrm{pH} 7.4$ ) for $2 \mathrm{~h}$ and then incubated with $50 \mu \mathrm{l}$ of 1: 2,000 dilution of rabbit pAb rGA733-2 for $2 \mathrm{~h}$, followed by $50 \mu \mathrm{l}$ of $1: 2000$ dilution of AP-conjugated goat anti-rabbit IgG (Thermo Scientific, USA) for $1 \mathrm{~h}$. $200 \mu \mathrm{l}$ of p-nitrophenyl phosphate $(1 \mathrm{mg} / \mathrm{ml}$; Sigma-Aldrich, USA) was added as a substrate for AP enzyme. The absorbance of the samples at $450 \mathrm{~nm}$ was monitored using a VERSA max microplate reader (Molecular Devices, USA).

\section{Purification of rGA733-Fc}

The leaves of transformed tobacco plants were ground in $0.5 \times$ PBS buffer. The soluble fraction was dialyzed against binding buffer $\left(10 \mathrm{mM} \mathrm{NaH}_{2} \mathrm{PO}_{4}\right.$ and $\left.150 \mathrm{mM} \mathrm{NaCl}, \mathrm{pH} 8.2\right)$. After filtration, total soluble proteins were passed through an Affi-Gel® Protein A Gel column (Bio-Rad Laboratories, CA, USA) at a flow rate of $0.5 \mathrm{ml} / \mathrm{min}$, and the column was washed with 10 bed volume binding buffer. Bound proteins were eluted by elution buffer ( $0.1 \mathrm{M}$ glycine, $\mathrm{pH} 3.0)$ at a flow rate of $0.5 \mathrm{ml} / \mathrm{min}$. The glycosylation patterns of plant-derived GA733-Fc proteins were analyzed by Matrixassisted laser desorption/ionization time-of-flight (MALDITOF) mass spectrometric (MS) analysis.

\section{In vitro flow cytometry analysis}

To test potential effects of plant-driven rGA733 and rGA733-Fc protein on progress of apoptosis in colorectal cancer cells, we performed in vitro flow cytometry analysis. The MC38 (Mouse colorectal cancer cell line) and the HCT116 (Human colorectal cancer cell line) cells $\left(2 \times 10^{6}\right.$ cells $/ 6 \mathrm{~cm}_{2}$ culture dish) were treated with the crude extract of non-transformed (NT) plants, $r G A 733^{O X}$ and $r G A 733$ $F c^{O X}$ transgenic plants. Human $\mathrm{Fc}$ protein $(\mathrm{h}-\mathrm{Fc}$ ) was used as a negative control for $\mathrm{Fc}$ domain of rGA733-Fc protein. After $48 \mathrm{~h}$ incubation, the cells were harvested and used for apoptosis analysis by flow cytometry using Modifit LT 3.0 and CellQuest software program.

\section{Genomic DNA extraction and PCR analysis of transgenic plants}

Genomic DNA was extracted from transgenic leaves to confirm the insertion of target DNA. $300 \mathrm{mg}$ of transgenic plant leaves were ground in liquid nitrogen and mixed thoroughly with $700 \mu \mathrm{l}$ of DNA extraction buffer $(0.05 \mathrm{M}$ Tris- $\mathrm{HCl}$, pH 7.6, 0.5\% SDS, $0.1 \mathrm{M} \mathrm{NaCl}, 0.05 \mathrm{M}$ EDTA, and $0.1 \mathrm{M}$ $\beta$-mercaptoethanol). The mixtures were incubated at $50^{\circ} \mathrm{C}$ for $10 \mathrm{~min}$, and then were thoroughly mixed with $500 \mu \mathrm{l}$ of phenol: chloroform: isoamylalcohol (25:24:1, Biosesang, Korea). The resulting extracts were centrifuged at $4{ }^{\circ} \mathrm{C}$ at $13,000 \mathrm{rpm}$ for $15 \mathrm{~min}$. After centrifugation, the supernatants were transferred to fresh tubes. 2 volumes of ethanol were added to the tubes and the tubes were inverted 5-10 times. The resulting genomic DNA extracts were centrifuged at $4{ }^{\circ} \mathrm{C}$ at $13,000 \mathrm{rpm}$ for $10 \mathrm{~min}$. The genomic DNA was washed with $75 \%$ ethanol and dissolved in distilled water. The presence of the GA733-2 gene was determined by PCR analysis using the specific primers GA733 RT-F (5'-GGC CGT AAA CTG CTT TGT GA-3') and GA733 RT-R (5' -CGC GTT GTG ATC TCC TTC TG-3'). After preheating the sample at $95{ }^{\circ} \mathrm{C}$ for $5 \mathrm{~min}, 34$ amplification cycles 
of $95{ }^{\circ} \mathrm{C}$ for $30 \mathrm{~s}, 55{ }^{\circ} \mathrm{C}$ for $30 \mathrm{~s}$, and $72{ }^{\circ} \mathrm{C}$ for 1 min were performed. A final incubation was conducted at $72{ }^{\circ} \mathrm{C}$ for 10 min.

\section{RNA extraction and real-time PCR analysis}

Total RNAs were extracted from leaves of tobacco plants using an RNeasy® Plant Mini Kit according to manufacturer's instruction (Qiagen, USA). $1 \mu \mathrm{g}$ of total RNAs was used for cDNA synthesis using a QuantiTect ${ }^{\circledR}$ Reverse Transcription Kit (Qiagen, USA). A genomic DNA was eliminated by the $7 \mathrm{X}$ gDNA Wipeout Buffer (Qiagen, USA) at $42^{\circ} \mathrm{C}$ for $2 \mathrm{~min}$. The sample was incubated for $1 \mathrm{~min}$ on ice and mixed with reverse-transcription master mix. cDNA synthesis was carried out at $42{ }^{\circ} \mathrm{C}$ for $15 \mathrm{~min}$ and at $95{ }^{\circ} \mathrm{C}$ for $3 \mathrm{~min} .1 \mu \mathrm{l}$ of cDNA was used for quantitative real-time PCR (qRTPCR) analysis using GA733-specific primers (GA733 RT-F and GA733 RT-R) and actin primers (Actin-F: 5'-TTGGAA

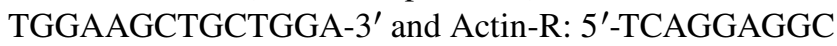
GCCACCACCTT-3'). After preheating the sample at $95^{\circ} \mathrm{C}$ for $5 \mathrm{~min}, 34$ amplification cycles $\left(95^{\circ} \mathrm{C}\right.$ for $30 \mathrm{~s}, 50^{\circ} \mathrm{C}$ for $30 \mathrm{~s}$, and $72{ }^{\circ} \mathrm{C}$ for $30 \mathrm{~s}$ ) were performed using a Rotor-gene Q PCR machine (Qiagen, USA).

\section{Results}

\section{Comparison of vector systems for transient expression of rGA733-2 in tobacco plants}

To test the effect of expression vector systems for the accumulation of rGA733-2 and rGA733-Fc proteins in tobacco plants, several expression vectors were constructed with Cauliflower Mosaic Virus $35 \mathrm{~S}$ promoter for overexpression and 5' UTR sequence from the tobacco etch virus for enhancing translation efficiency. Since low protein stability of recombinant proteins in cytosols has frequently emerged as a major limitation for production of recombinant protein in plants, a plant ER targeting signal peptide and ER retention codon were fused to rGA733-2 and rGA733-Fc coding sequence to target rGA733-2 and rGA733-Fc to the ER (Fig. 1a). Agrobacterium-mediated transient expression system was applied to validate efficiency of the constructs for rGA733-2 protein expression in tobacco plants. Western blot analysis showed that rGA733-2 proteins were clearly detected in tobacco plants when infected with the pBINPLUS and the pPZP-Bar vector systems but not by the pBI121 and the pPZP-200 vector systems (Fig. 1b). Similarly, rGA733-Fc protein was highly expressed with the pBINPLUS and the pPZP-Bar vector systems (Fig. 1c). These results suggest that backbone of plant expression vectors affects expression level of rGA733-2/rGA733-Fc proteins in tobacco plants.

\section{Expression level of rGA733 is affected by length of interval between the rGA733 expression cassette and left border of T-DNA}

We found that the rGA733 protein was efficiently expressed by the pPZP-Bar but not by the pPZP-200 vector system even though we introduced the identical expression cassette into the vectors. As the pPZP-Bar vector has identical structure with pPZP-200 except for the existence of the Bar gene, we compared these two systems to understand the observed phenomenon. We first replaced Bar gene in pPZP-Bar-GA733 expression vector with Bacillus subtilis NADPH-cytochrome P450 reductase 102A2V4gene (CYP) to test whether presence of antibiotic resistance gene affects expression of rGA733 protein in plants (Fig. 2a). Western analysis showed that expression level of rGA733 was unaffected by the replacement of the Bar gene to the CYP gene (Fig. 2b), suggesting that the presence of antibiotic resistance gene is unnecessary for the expression of rGA733 protein. We then hypothesized that length of downstream interval between expression cassette and left border of T-DNA might be important for the expression of rGA733 protein in tobacco plant. To test the possibility, we constructed rGA733 expression vectors with insertions of various length of DNA fragments $(0.2-2 \mathrm{~kb})$ between rGA733 expression cassette and left border of T-DNA in the pPZP200-GA733 vector (Fig. 2c, d). Interestingly, we observed a positive correlation in length of inserted DNA fragments between the rGA733 gene and left border of T-DNA and expression level of proteins. Specifically, insertion of DNA fragments longer than $0.8 \mathrm{~kb}$ greatly increased rGA733 protein expression (Fig. 2d). Further quantitative real time PCR (qRT-PCR) analysis showed that expression level of rGA733 was two-fold higher in tobacco plants transfected by the pPZP-2 kb-GA733 than pPZP-GA733 vector (Fig. 2c). Collectively, these results suggest that the interval longer than $0.8 \mathrm{~kb}$ between rGA733 expression cassette and left border of T-DNA increases rGA733 expression in tobacco plants.

\section{Effect of tobacco cultivars (N. tabacum cv.Xanthi nc and $\boldsymbol{N}$. benthamiana) and Agrobacterium strains (C58C1, LBA4404, and GV3101) on expression of rGA733-2 and rGA733-Fc proteins}

Although the tobacco system is suitable for robust expression of heterogeneous protein, it is known that there exit huge variations in the expression levels of recombinant protein depending on the combination of tobacco species and A. tumefaciens strains used for transient expression (Shamloul et al. 2014). Thus, it is important to determine appropriate combination of tobacco species and A. tumefaciens strains to maximize recombinant protein expression. 
a

pBI121-

GA733/GA733-Fc

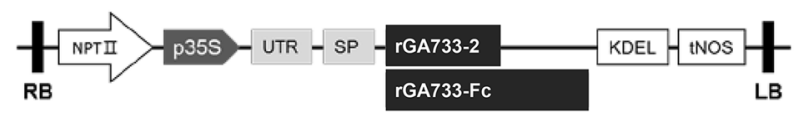

PBINPLUS-

GA733/GA733-Fc

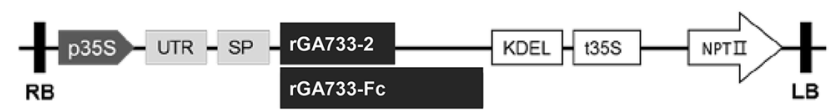

PPZP-200-

GA733/GA733-Fc

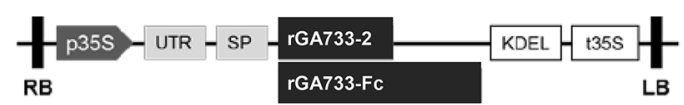

pPZP-Bar-

GA733/GA733-Fc
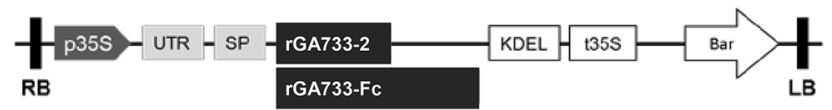

b

C

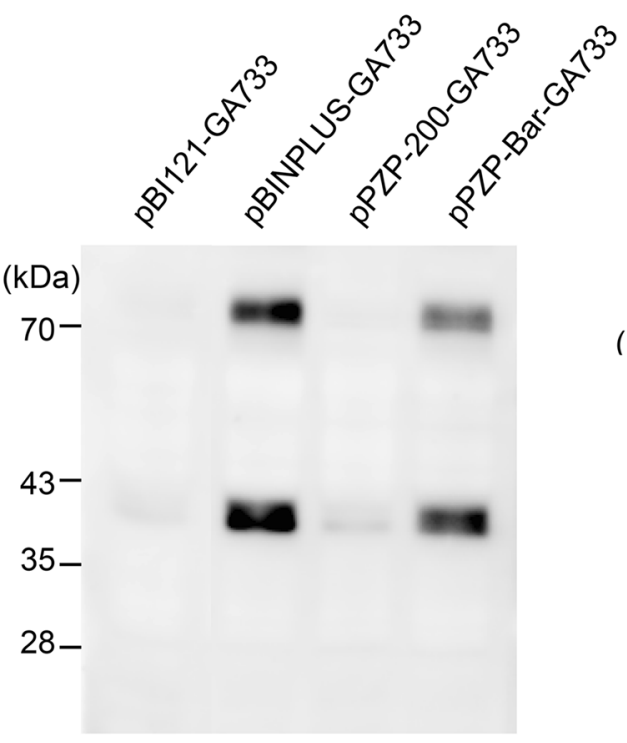

Fig. 1 Construction of rGA733-2 and rGA733-Fc plant expression vectors. a The schematic diagram of the plant expression vectors constructed for expressing rGA733-2 and rGA733-Fc protein in plants. $\mathrm{LB}$ and RB, left and right T-DNA borders; $p 35 S$, Cauliflower Mosaic Virus $35 S$ promoters; UTR, $5^{\prime}$ UTR from the tobacco etch virus; SP, 30-aa plant ER signal peptide; KDEL, endoplasmic reticulum (ER) retention codon; tNOS, nopaline synthase terminator; NPT II, neomy-

We, therefore, tested the effect of tobacco cultivars $(N$. tabacum cv.Xanthi nc and N. benthamiana) and Agrobacterium strains (C58C1, LBA4404, and GV3101) on the expression levels of rGA733-2 and rGA733-Fc proteins in tobacco plants (Fig. 3). We also monitored protein levels for 9 days to determine optimal incubation time for robust productions of rGA733-2 and rGA733-Fc protein in tobacco plants. Accumulation of rGA733 and rGA733-Fc protein increased during first 3 days after infiltration, and then continuously decreased in all tested conditions. These results

cin phosphotransferase II; Bar, phosphinothricin N-acetyltransferase protein. Expression levels of the rGA733-2 protein (b) and rGA733Fc (c) in tobacco plants. Agrobacterium tumefaciens GV3101 strain harboring the indicated constructs were infiltrated into tobacco leaves. The level of rGA733-2 and rGA733-Fc was determined by western analysis using the GA733 specific antibody

indicate that 3 days after infiltration is optimal time point for robust expression of rGA733-2 and rGA733-Fc in tobacco plants. The type of Agrobacterium strains caused only subtle differences on the expression levels of both rGA733-2 and rGA733-Fc in N. tabacum plants. However, in N. benthamiana plants, the A. thumefaciens LBA4404 strain showed five-fold higher efficiency than C58C1 and GV3101 strains on the expression of rGA733-2 and rGA733-Fc proteins. The highest expression level of the rGA733-2 was $15.92 \mu \mathrm{g} / \mathrm{g}$ and that of the rGA733-Fc was $51.28 \mu \mathrm{g} / \mathrm{g}$ (Fig. 3). Collectively, 
a pPZP-200-GA733

pPZP-Bar-GA733

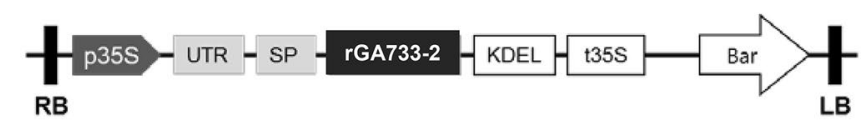

pPZP-2Kb-GA733
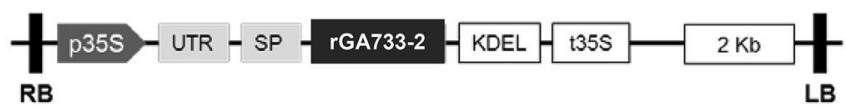

b

\section{C}
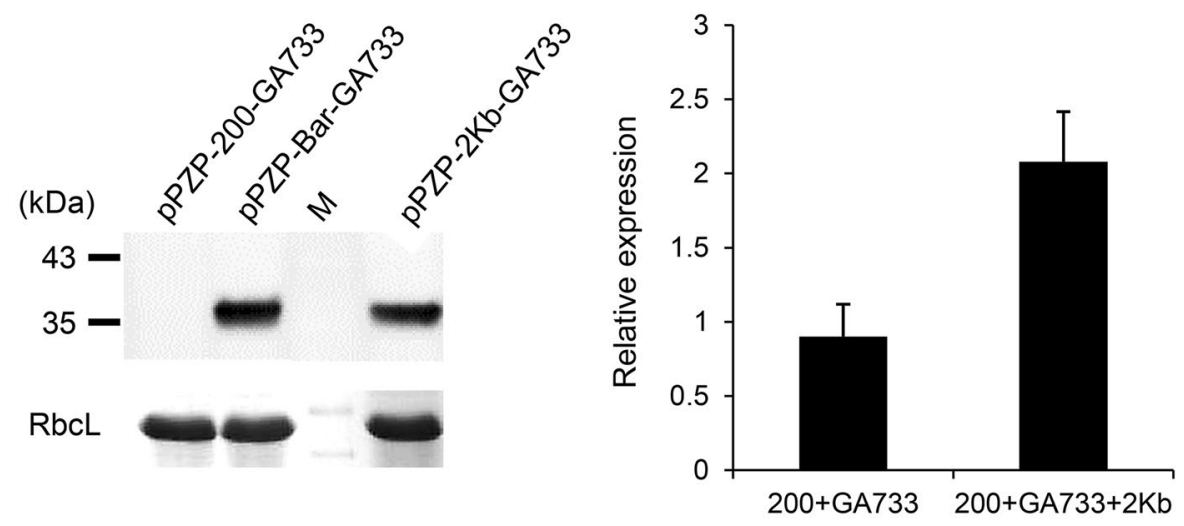

d

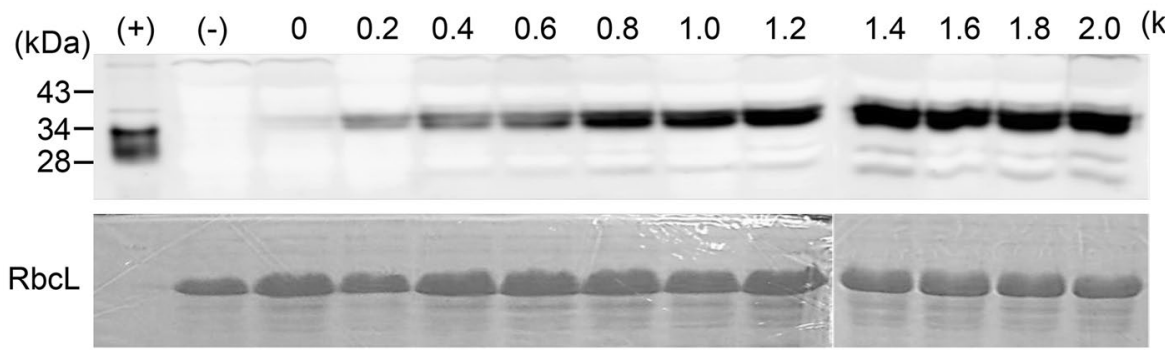

Fig. 2 The effect of $3^{\prime}$ interval for rGA733-2 protein expression in plants. a The schematic diagram of three plant expression vectors. LB and RB, left and right T-DNA borders; $p 35 S$, Cauliflower Mosaic Virus $35 S$ promoters; UTR, 5' UTR from the tobacco etch virus; SP, 30-aa plant ER signal peptide; KDEL, endoplasmic reticulum (ER) retention codon; Bar, phosphinothricin $\mathrm{N}$-acetyltransferase protein; $2 \mathrm{~Kb}$, Bacillus subtilis NADPH-cytochrome P450 reductase 102A2V4 gene. Expression level of rGA733-2 protein (b) and transcripts (c) in tobacco plants infiltrated with the indicated constructs (d) The effect

these data indicate that LBA4404-mediated transient expression of rGA733-2 and rGA733-Fc greatly increases protein expression efficiency in tobacco ( $N$. benthamiana) plants.

\section{Generation of transgenic tobacco plants expressing rGA733-2/rGA733-FC}

Generation of transgenic plants is important for stable and low-cost production of recombinant proteins (Mason of $3^{\prime}$ interval between $35 S$ terminator and left border of T-DNA. Different size of DNA fragments was inserted between the $35 \mathrm{~S}$ terminator and left border of the pPZP-200 vector. The level of rGA733-2 protein was determined by western analysis using the GA733 specific antibody. Rubisco large subunit (RbcL) was used as a loading control. Relative expression level of rGA733-2 was determined by quantitative real time PCR (qRT-PCR). The SlACTIN gene was used as an internal control. Data represent mean + standard deviation (SD) of three technical replicates

et al. 2002). To achieve stable expression of rGA733-2 and rGA833-Fc protein in plants, we generated transgenic tobacco plants overexpressing rGA733 (rGA733-2 $\left.{ }^{O X}\right)$ (Fig. 4a) and $r G A 733-F c\left(r G A 733-F c^{O X}\right)$ (Fig. 4b), respectively. PCR analysis using genomic DNA confirmed the existence of transgene cassettes in tobacco plants. Further western analysis showed that rGA733-2 and rGA733-Fc proteins were expressed in all the selected transgenic plants. Among the selected transgenic plants, $r G A 733-2^{O X} \# 3$ and 
rGA733

(N.tabacum)
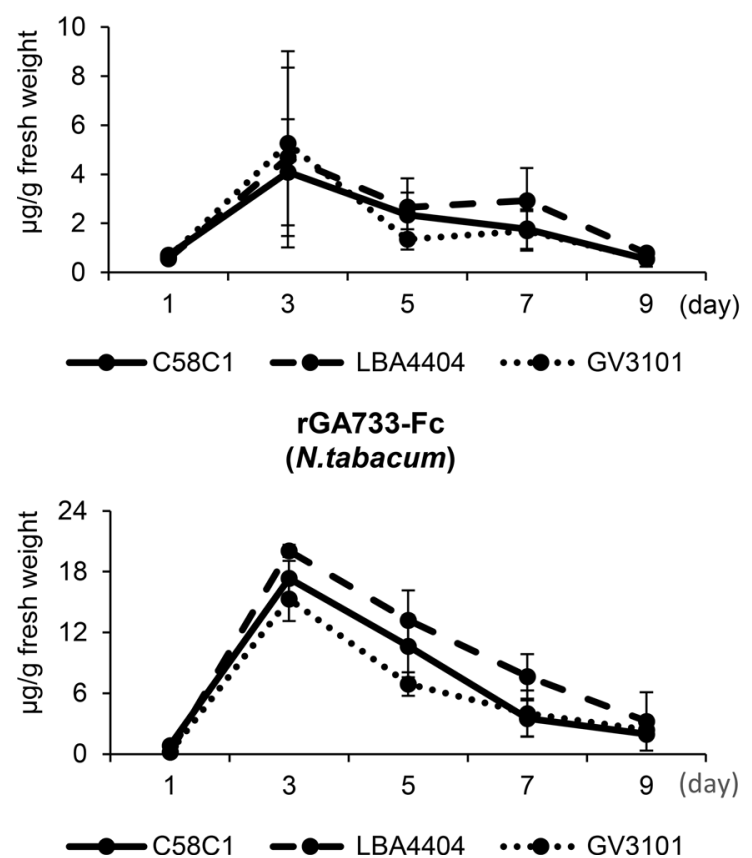

Fig. 3 Effect of A. tumefaciens strains and tobacco species on rGA733-2/rGA733-Fc expression. Six-week-old Nicotiana benthamiana (N. benthamiana) and Nicotiana tabacum ( N. tabacum) plants grown on soils were infiltrated with three different Agrobacterium tumefaciens strains (C58C1, LBA4404, and GV3101) harboring

rGA733-Fc $c^{O X} \# 2$ transgenic tobacco exhibited the highest protein expression level (Fig. 4). The rGA733-2 protein level in $r G A 733-2^{O X} \# 3$ leaves was $3.12 \mu \mathrm{g} / \mathrm{g}$ fresh weight, and the level of gRNA733-Fc was $5 \mu \mathrm{g} / \mathrm{g}$ fresh weight in the $r G A 733-F C^{O X} \# 2$ leaves.

\section{In vitro analysis for evaluating biological functions of rGA733/rGA733-Fc from transgenic tobacco plants}

To confirm the biological functionality of plant-driven rGA733 and rGA733-Fc protein, we performed in vitro flow cytometry analysis using crude extracts of tobacco plants (Fig. 5). The apoptosis progression induced by the crude extracts was monitored in the MC38 (Mouse colorectal cancer cell line) and the HCT116 (Human colorectal cancer cell line) cells. Non-transformed (NT) plants were used as negative controls for $r G A 733^{O X}$ and $r G A 733-F c^{O X}$ transgenic plants. Human $\mathrm{Fc}$ protein $(\mathrm{h}-\mathrm{Fc}$ ) was used as a negative control for $\mathrm{Fc}$ domain of rGA733-Fc protein. MC38 and HCT116 cells $\left(2 \times 10^{6}\right.$ cells $/ 6$ $\mathrm{cm}_{2}$ culture dish) were treated with the crude extracts of NT, in $r G A 733-2^{O X}$, and $r G A 733-F c^{O X}$ and Human $\mathrm{Fc}$ protein for $48 \mathrm{~h}$. The extracts of NT plants induced $49 \%$ of apoptosis in MC38 cells. Simultaneous treatments of h-Fc caused to
rGA733

(N.benthamiana)
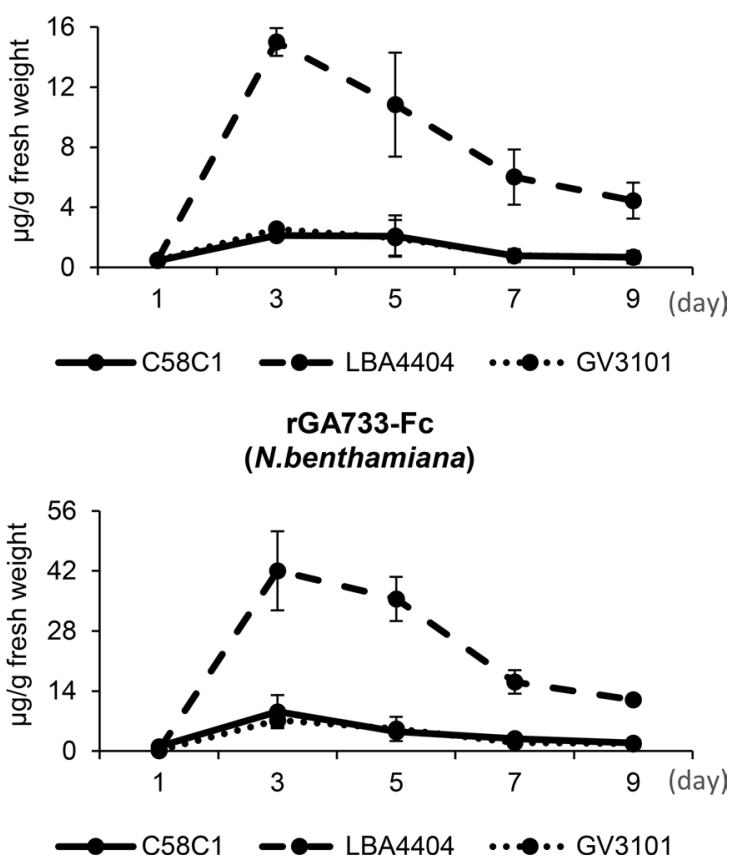

pBINPLUS-GA733 or pBINPLUS-GA733-Fc expression vectors. The infected leaves were harvested at the indicated time points after infiltration. Protein levels were quantified ELISA analysis. Data represent mean \pm standard deviation (SD) of three replicates

induction of apoptosis from $55 \%$ of the treated cells. Under same conditions, $r G A 733-2^{O X}$ and $r G A 733-F c^{O X}$ extracts induced $51 \%$ and $68 \%$ of apoptosis, respectively. In HCT116 cells, the extracts of NT and $r G A 733^{O X}$ plants induced $49 \%$ of apoptosis. Under same conditions, $r G A 733-F c^{O X}$ extracts induced $54 \%$ of apoptosis. As a result, the apoptosis progression of MC38 and HCT116 cells were induced by treatment of plant derived GA733-Fc (Fig. 5). These results suggest that plant-derived GA733-Fc suppresses the tumorigenicity of both MC38 and HCT116 carcinoma cells by inducing apoptosis.

\section{Purification and analysis of $\mathrm{N}$-glycosylation of plant-derived rGA733-Fc protein}

Purification of plant-derived recombinant protein is necessary for the use of the recombinant protein as a vaccine candidate. The presence of the Fc domain improves stability of fusion protein and allows cost-effective purification during manufacture (Carter 2011; Czajkowsky et al. 2012). Thus, rGA733-Fc recombinant proteins generated by stable transformation were purified using a protein A column. Coomassie brilliant blue staining showed that most of the purified proteins were detected in specific elution fractions (Fig. 6a). The bands were further confirmed 


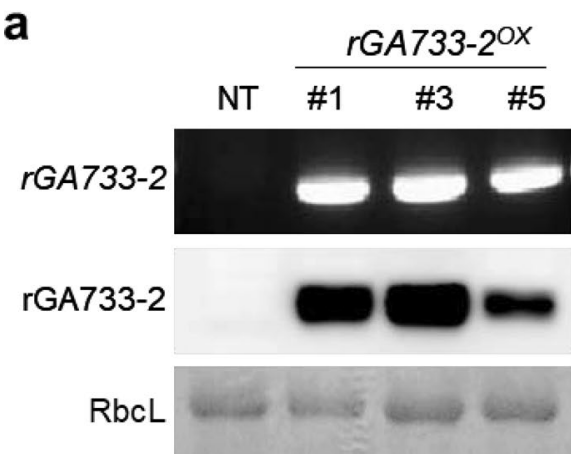

b

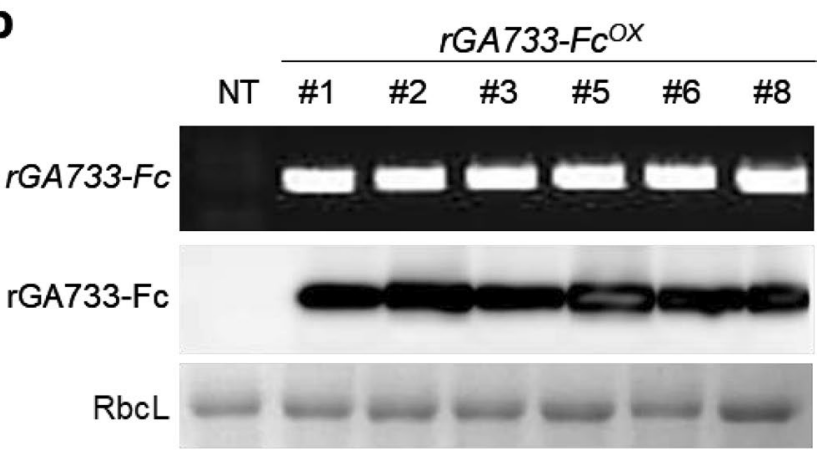

Fig. 4 Characterization of transgenic tobacco plants expressing rGA733-2/rGA733-Fc protein. Transgenic tobacco plants expressing rGA733-2 (a) and rGA733-Fc (b) were generated using Agrobacterium-mediated transformation method with pBINPLUS-GA733 and pBINPLUS-GA733-Fc plant expression vectors. The transgenic plants were analyzed by genomic DNA PCR and western blot analysis. NT, non-transgenic tobacco plants

MC38 48h

Un

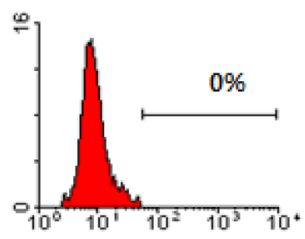

Con

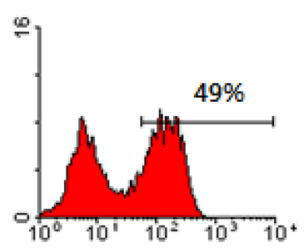

h-Fc

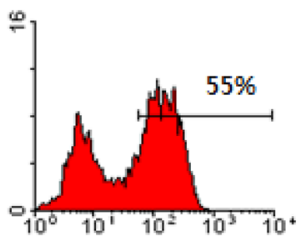

GA733-Fc

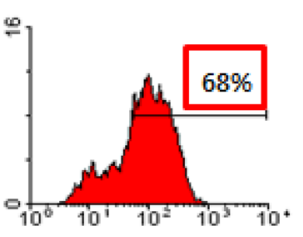

GA733

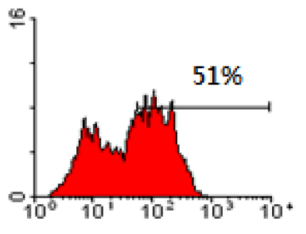

$\mathrm{Pl}+$ Annexin $\mathrm{V}$

HCT116 48h

Un

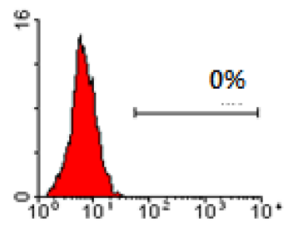

Con

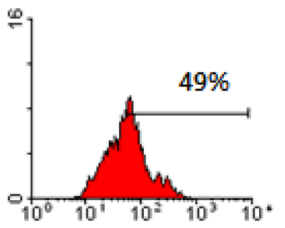

h-Fc

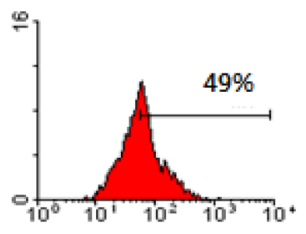

GA733-Fc

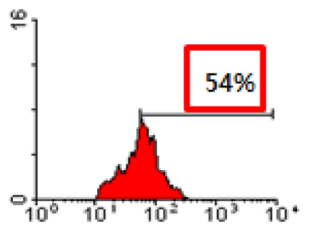

GA733

$\mathrm{PI}+$ Annexin $\mathrm{V}$

Fig. 5 The plant-derived GA733-Fc regulated the apoptosis in MC38 and HCT116 cells. MC38 and HCT116 cells were treated with the extracts of non-transgenic, $r G A 733-2^{O X}$ and $r G A 733-F c^{O X}$ plants for $48 \mathrm{~h}$. The apoptosis analysis was performed by flow cytometry using a Modifit LT 3.0 and a CellQuest software program. Un, Un-treated; Con, non-transgenic tobacco plants; h-Fc, human Fc protein; GA733$\mathrm{Fc}$, extracts of $r G A 733-F^{O X}$ plants; GA733, extracts of $r G A 733-2^{O X}$ plants as rGA733-Fc proteins by western blot analysis using a rGA733 specific antibody (Park et al. 2015a) (Fig. 6b). In addition to rGA733-Fc band, additional band above $70 \mathrm{kDa}$ was detected by western blot analysis. Similar with our results, Verch et al. reported that rGA733-Fc dimer was detected by western blot analysis (Verch et al. 2004). Final concentration of purified rGA733-Fc was $4.67 \mathrm{ug} / \mathrm{g}$ from $r G A 733-F c^{O X}$ transgenic plants. As a glycan structure is an important feature for application of a recombinant protein as a vaccine candidate, we next examined glycosylation patterns of the purified rGA733-Fc proteins by
MALDI-TOF MS analysis. rGA733-Fc proteins obtained by stable transformation contained oligomannose glycan structures, which are typical patterns detected from ERassociated proteins (Fig. 6c).

\section{Discussion}

Plant systems have been extensively used as a biological factory for production of therapeutic recombinant proteins (Shanmugaraj et al. 2020, Takeyama et al. 2015). However, 
a

b

T FT W E1 E2 E3 E4 E5 E6 E7 E8 E9 E10 E11 E12 E13

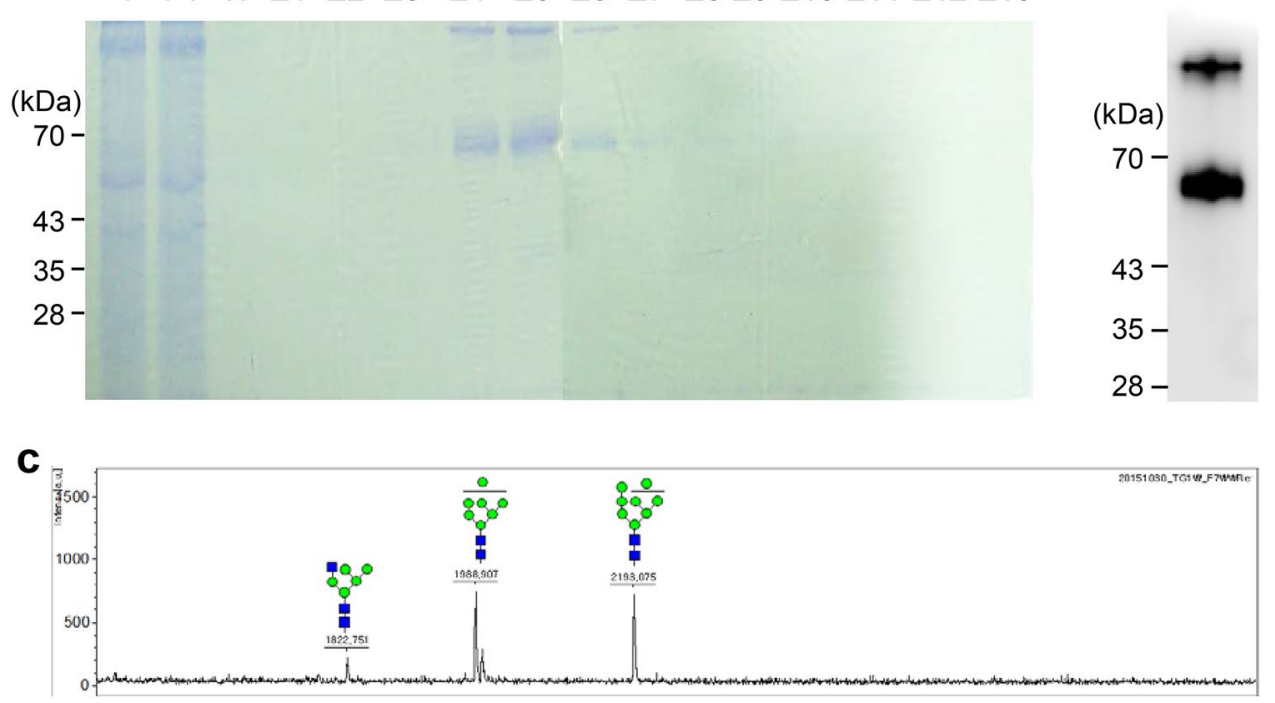

Fig. 6 Glycosylation patterns of plant-derived rGA733-Fc protein. rGA733-Fc protein was purified from the $r G A 733-F c^{O X}$ transgenic tobacco leaves using a protein A column. The fractions that contain rGA733-Fc were determined by SDS-PAGE (a) and western blot analysis (b) using the GA733 specific antibody. T, total soluble protein; FT, flow through; W, flow-through by washing; E1-E13, eluted fractions. c Glycosylation patterns of the purified rGA733-Fc protein. The glycosylation patterns of plant-derived rGA733-Fc proteins were analyzed by Matrix-assisted laser desorption/ionization time-offlight (MALDI-TOF) mass spectrometric (MS) analysis. Blue square, $\mathrm{N}$-acetylglucosamine (GlcNAc); green circle, mannose

rGA733-2 transcripts. $r G A 733-2$ expression level was lower in tobacco plants when infected with pPZP-200-GA733 than with pPZP-2 kb-GA733 (Fig. 2b). It will be interesting to further examine effects of the interval on the expression of other recombinant proteins in plants.

The efficiency of transient expression is largely affected by both A. tumefaciens strains and host tobacco species (Nausch et al. 2012; Prado et al. 2019; Shamloul et al. 2014). rGA733-2 protein was expressed at similar levels in N. tabacum plants, regardless of the A. tumefaciens strains used for transient expressions. One the other hand, in N. benthamiana, the A. tumefaciens LBA4404 strain was more efficient than other two strains for rGA733-2 and rGA733-Fc expression. Under the conditions, we detected more than five-fold higher concentration of rGA733-2 and rGA733-Fc proteins, compared with other tested conditions (Fig. 3). Our results suggest ideal combination of $A$. tumefaciens strain and host tobacco species for transient expression of GA733-2 and GA733-Fc in tobacco plants, which is beneficial for rapid production of vaccine candidates in tobacco plants.

Fc chain has been known to improve stability and yield of recombinant proteins (Czajkowsky et al. 2012; De Buck et al. 2013; Obregon et al. 2006). Fusion of Fc chain to HIV p13 antigen resulted in 13-fold increase of the protein accumulation in tobacco plants (Obregon et al. 2006). Similarly, accumulation of Nanobodies VHH7 in Arabidopsis seeds increased 10- to 100-fold by fusion with an Fc chain (De 
Buck et al. 2013). Fusion of an Fc chain to the rGA733 resulted in approximately three-fold higher accumulation levels (Fig. 3). Thus, fusion of rGA733-2 with an Fc chain improve stability of rGA733-2 protein, leading to increase accumulation of rGA733-2 in tobacco plants.

Fc fragment fusion to recombinant proteins not only increases protein accumulation but also facilitates onestep purification procedure using the protein A column (Ashkenazi and Chamow 1997; Czajkowsky et al. 2012). Gel staining and western blot analysis confirmed that rGA733-Fc proteins was efficiently accumulated by protein A column (Fig. 6). Potential disadvantage of Fc fusion of recombinant protein is the generation of degradation products (Castilho et al. 2011; De Buck et al. 2013; Lu et al. 2012). Compared to these reports, a negligible amount of degradation fragments was detected in our study (Fig. 6b). The less degradation of rGA733-Fc might be explained by ER retention of rGA733-Fc proteins. C-terminal fusion of KDEL ER retention codon has been proved to trigger localization of fusion protein into ER (Fu et al. 2018). ER targeting of recombinant proteins increases accumulation of recombinant proteins in plants due to relatively high chaperone activity and low protease activity in ERs (Benchabane et al. 2008; Lu et al. 2012; Schouten et al. 1996; Ullrich et al. 2015). In vitro apoptosis test revealed that the rGA733-Fc was more efficient than rGA733-2 protein to induce apoptosis in cells (Fig. 5). It has been reported that fusion of Fc fragment to recombinant proteins stimulated an increase in phagocytosis, the release of inflammatory mediators, antibody-dependent cellular cytotoxicity, endocytosis, and the antigen presentation response in cells (Czajkowsky et al. 2012; Otten and van Egmond 2004). Collectively, fusion of rGA733-2 with both $\mathrm{Fc}$ chain and ER retention codon can be used to increase both productivity and functionality of rGA733-2 protein in tobacco plants.

For production of recombinant proteins for vaccine candidates, it is essential to determine glycosylation patterns of the produced recombinant protein (Bosch and Schots 2010; Hariharan and Kane 2020; Van Droogenbroeck et al. 2007), because plant-specific N-glycosylation patterns, such as $\beta-1,2$-xylose and $\alpha-1,3$-fucose, which are generated during protein process in Golgi, are often allergenic for mammalian system (Bakker et al. 2001; Schoberer and Strasser 2018; Wilson et al. 2001). Targeting of recombinant proteins into ER is known to bypass these plant-specific glycosylation patterns (Nausch et al. 2012). Glycosylation pattern analysis revealed that the rGA733Fc protein fused with KDEL ER retention codon had oligomannose glycan structures, which are typical glycosylation patterns found on ER-associated proteins (Schoberer and Strasser 2018) (Fig. 6c). These results indicate that the KDEL ER retention codon is suitable for preventing unnecessary glycosylation patterns on rGA733 recombinant protein. In this study, we provide useful information to develop efficient strategy to produce rGA733-2 recombinant protein in tobacco systems.

Acknowledgements This work was supported by a grant from the New breeding technologies development Program (Project No. PJ01487401), and the Next-Generation BioGreen21 Program (Project No. PJ01389401), Rural Development Administration, Republic of Korea.

\section{References}

Abakushina EV, Gelm YV, Pasova IA, Bazhin AV (2019) Immunotherapeutic approaches for the treatment of colorectal cancer. Biochemistry (Mosc) 84:720-728

Armstrong A, Eck SL (2003) EpCAM: A new therapeutic target for an old cancer antigen. Cancer Biol Ther 2:320-326

Ashkenazi A, Chamow SM (1997) Immunoadhesins as research tools and therapeutic agents. Curr Opin Immunol 9:195-200

Bakker H, Bardor M, Molthoff JW, Gomord V, Elbers I, Stevens LH, Jordi W, Lommen A, Faye L, Lerouge P, Bosch D (2001) Galactose-extended glycans of antibodies produced by transgenic plants. Proc Natl Acad Sci U S A 98:2899-2904

Basak S, Speicher D, Wunner W, Maul G, Herlyn D, Eck S, Simmons MS (1998) Colorectal carcinoma invasion inhibition by CO171A/GA733 antigen and its murine homologue. J Natl Cancer Inst 90:691-697

Benchabane M, Goulet C, Rivard D, Faye L, Gomord V, Michaud D (2008) Preventing unintended proteolysis in plant protein biofactories. Plant Bioechnol J 6:633-648

Blokhina EA, Mardanova ES, Stepanova LA, Tsybalova LM, Ravin NV (2020) Plant-produced recombinant Influenza A virus candidate vaccine based on flagellin linked to conservative fragments of M2 protein and hemagglutintin. Plants 9:162

Bosch D, Schots A (2010) Plant glycans: friend or foe in vaccine development? Expert Rev Vaccines 9:835-842

Bracci L, Fragale A, Gabriele L, Moschella F (2020) Towards a systems immunology approach to unravel responses to cancer immunotherapy. Front Immunol 11:1

Bradley DW, Zaitlin M (1971) Replication of tobacco mosaic virus: II. The in vitro synthesis of high molecular weight virus-specific RNAs. Virol J 45:192-199

Brodzik R, Glogowska M, Bandurska K, Okulicz M, Deka D, Ko K, van der Linden J, Leusen JH, Pogrebnyak N, Golovkin M, Steplewski Z, Koprowski H (2006) Plant-derived anti-Lewis $\mathrm{Y}$ mAb exhibits biological activities for efficient immunotherapy against human cancer cells. Proc Natl Acad Sci USA 103:8804-8809

Brodzik R, Spitsin S, Golovkin M, Bandurska K, Portocarrero C, Okulicz M, Steplewski Z, Koprowski H (2008) Plant-derived EpCAM antigen induces protective anti-cancer response. Cancer Immunol Immunother 57:317-323

Carter PJ (2011) Introduction to current and future protein therapeutics: a protein engineering perspective. Exp Cell Res 317:1261-1269

Castilho A, Gattinger P, Grass J, Jez J, Pabst M, Altmann F, Gorfer M, Strasser R, Steinkellner H (2011) N-Glycosylation engineering of plants for the biosynthesis of glycoproteins with bisected and branched complex N-glycans. Glycobiology 21:813-823

Czajkowsky DM, Hu J, Shao Z, Pleass RJ (2012) Fc-fusion proteins: new developments and future perspectives. EMBO Mol Med 4:1015-1028 
Daniell H, Singh ND, Mason H, Streatfield SJ (2009) Plant-made vaccine antigens and biopharmaceuticals. Trends Plant Sci 14:669-679

Daniell H, Streatfield SJ, Wycoff K (2001) Medical molecular farming: production of antibodies, biopharmaceuticals and edible vaccines in plants. Trends Plant Sci 6:219-226

De Buck S, Nolf J, De Meyer T, Virdi V, De Wilde K, Van Lerberge E, Van Droogenbroeck B, Depicker A (2013) Fusion of an Fc chain to a $\mathrm{VHH}$ boosts the accumulation levels in Arabidopsis seeds. Plant Biotechnol J 11:1006-1016

Fox J (2012) First plant-made biologic approved. Nat Biotechnol 30:472-472

Francis MJ (2018) Recent advances in vaccine technologies. Vet Clin North Am Small Anim Pract 48:231-241

Fu Y-Y, Zhao J, Park J-H, Choi G-W, Park K, Lee Y, Chung I (2018) Human colorectal cancer antigen GA733-2-Fc fused to endoplasmic reticulum retention motif KDEL enhances its immunotherapeutic effects. J Cancer Res Ther 14:748-757

Golovkin M, Spitsin S, Andrianov V, Smirnov Y, Xiao Y, Pogrebnyak N, Markley K, Brodzik R, Gleba Y, Isaacs SN, Koprowski $H$ (2007) Smallpox subunit vaccine produced in planta confers protection in mice. Proc Natl Acad Sci USA 104:6864-6869

Grosse-Holz F, Kelly S, Blaskowski S, Kaschani F, Kaiser M, van der Hoorn RAL (2018) The transcriptome, extracellular proteome and active secretome of agroinfiltrated Nicotiana benthamiana uncover a large, diverse protease repertoire. Plant Biotechnol J 16:1068-1084

Hariharan V, Kane RS (2020) Glycosylation as a tool for rational vaccine design. Biotechnol Bioeng 117:2556-2570

Horsch RB, Fry J, Hoffmann N, Neidermeyer J, Rogers SG, Fraley RT (1989) Leaf disc transformation. In: Gelvin SB, Schilperoort RA, Verma DPS (eds) Plant Molecular Biology Manual. Springer, Dordrecht

Jakob F, Lehmann C, Martinez R, Schwaneberg U (2013) Increasing protein production by directed vector backbone evolution. AMB Express 3:39

Joung YH, Park SH, Moon K-B, Jeon J-H, Cho H-S, Kim H-S (2016) The last ten years of advancements in plant-derived recombinant vaccines against Hepatitis B. Int J Mol Sci 17:1715

Koido S (2013) Immunotherapy for colorectal cancer. World J Gastroenterol 19:8531

Lee JH, Ko K (2017) Production of recombinant anti-cancer vaccines in plants. Biomol Ther 25:345-353

Li W, Berencsi K, Basak S, Somasundaram R, Ricciardi RP, Gönczöl E, Zaloudik J, Linnenbach A, Maruyama H, Miniou P, Herlyn D (1997) Human colorectal cancer (CRC) antigen CO17-1A/GA733 encoded by adenovirus inhibits growth of established CRC cells in mice. J Immunol Res 159:763-769

Lim CY, Lee KJ, Oh DB, Ko K (2014) Effect of the developmental stage and tissue position on the expression and glycosylation of recombinant glycoprotein GA733-FcK in transgenic plants. Front Plant Sci 5:778

Lomonossoff GP, D’Aoust MA (2016) Plant-produced biopharmaceuticals: a case of technical developments driving clinical deployment. Science 353:1237-1240

Lu Z, Lee K-J, Shao Y, Lee J-H, So Y, Choo Y-K, Oh D-B, Hwang K-A, Oh SH, Ham YS, Ko K (2012) Expression of GA733-Fc fusion protein as a vaccine candidate for colorectal cancer in transgenic plants. BioMed Res Int 2012:364240

Mamaloudis I, Zacharoulis D, Samara M, Papadopoulos G, Samara S, Koukoulis G, Chatzitheofilou C, Kollia P (2015) Expression profile of the GA733 gene family in colorectal cancer: correlation with clinicopathological parameters. Genet Mol Res 14:14772-14781

Mardanova ES, Blokhina EA, Tsybalova LM, Peyret H, Lomonossoff GP, Ravin NV (2017) Efficient transient expression of recombinant proteins in plants by the novel $\mathrm{pEff}$ vector based on the genome of potato virus x. Front Plant Sci 8:1

Mason HS (2016) Recombinant immune complexes as versatile and potent vaccines. Hum Vaccin Immunother 12:988-989

Mason HS, Warzecha H, Mor T, Arntzen CJ (2002) Edible plant vaccines: applications for prophylactic and therapeutic molecular medicine. Trends Mol Med 8:324-329

McCormick AA (2011) Tobacco derived cancer vaccines for nonHodgkin's lymphoma: perspectives and progress. Hum Vaccin 7:305-312

McCormick AA, Reddy S, Reinl SJ, Cameron TI, Czerwinkski DK, Vojdani F, Hanley KM, Garger SJ, White EL, Novak J, Barrett J, Holtz RB, Tusé D, Levy R (2008) Plant-produced idiotype vaccines for the treatment of non-Hodgkin's lymphoma: Safety and immunogenicity in a phase I clinical study. Proc Natl Acd Sci U S A 105:10131-10136

Nausch H, Mikschofsky H, Koslowski R, Meyer U, Broer I, Huckauf J (2012) High-Level Transient Expression of ER-Targeted Human Interleukin 6 in Nicotiana benthamiana. PLoS ONE 7:e48938

Obregon P, Chargelegue D, Drake PMW, Prada A, Nuttall J, Frigerio L, Ma JKC (2006) HIV-1 p24-immunoglobulin fusion molecule: a new strategy for plant-based protein production. Plant Biotechnol J 4:195-207

Otten MA, van Egmond M (2004) The Fc receptor for IgA (FcalphaRI, CD89). Immunol Lett 92:23-31

Park SH, Kim A-Y, Ma SH, Kim HM, Kang HS, Maeng J-S, Ko K, Chung IS, Joung YH (2015a) Purification of human carcinoma antigen GA733-2 expressed in Escherichia coli and production of its polyclonal antibody in rabbit. Anim Cells Syst 19:188-193

Park SR, Lim CY, Kim DS, Ko K (2015b) Optimization of ammonium sulfate concentration for purification of colorectal cancer vaccine candidate recombinant protein $\mathrm{GA} 733-\mathrm{FcK}$ isolated from plants. Front Plant Sci 6:1040

Pinkhasov J, Alvarez ML, Rigano MM, Piensook K, Larios D, Pabst M, Grass J, Mukherjee P, Gendler SJ, Walmsley AM, Mason HS (2011) Recombinant plant-expressed tumour-associated MUC1 peptide is immunogenic and capable of breaking tolerance in MUC1.Tg mice. Plant Biotechnol J 9:991-1001

Prado GS, Bamogo PKA, de Abreu JAC, Gillet F-X, dos Santos VO, Silva MCM, Brizard J-P, Bemquerer MP, Bangratz M, Brugidou C, Sérémé D, Grossi-de-Sa MF, Lacombe S (2019) Nicotiana benthamiana is a suitable transient system for high-level expression of an active inhibitor of cotton boll weevil $\alpha$-amylase. BMC Biotechnol 19:15

Rajaram S, Boikos C, Gelone DK, Gandhi A (2020) Influenza vaccines: the potential benefits of cell-culture isolation and manufacturing. Ther Adv Vaccines Immunother 8:2515135520908121-2515135520908121

Rosales-Mendoza S, Angulo C, Meza B (2016) Food-grade organisms as vaccine biofactories and oral delivery vehicles. Trends Biotechnol 34:124-136

Rybicki EP (2009) Plant-produced vaccines: promise and reality. Drug Discov Today 14:16-24

Saejung W, Fujiyama K, Takasaki T, Ito M, Hori K, Malasit P, Watanabe Y, Kurane I, Seki T (2007) Production of dengue 2 envelope domain III in plant using TMV-based vector system. Vaccine 25:6646-6654

Sarvizadeh M, Ghasemi F, Tavakoli F, Sadat Khatami S, Razi E, Sharifi H, Biouki NM, Taghizadeh M (2019) Vaccines for colorectal cancer: an update. J Cell Biochem 120:8815-8828

Schillberg S, Raven N, Spiegel H, Rasche S, Buntru M (2019) Critical analysis of the commercial potential of plants for the production of recombinant proteins. Front Plant Sci 10:720-720

Schoberer J, Strasser R (2018) Plant glyco-biotechnology. Sem Cell Dev Biol 80:133-14 
Schouten A, Roosien J, van Engelen FA, de Jong GA, Borst-Vrenssen AW, Zilverentant JF, Bosch D, Stiekema WJ, Gommers FJ, Schots A, Bakker J (1996) The C-terminal KDEL sequence increases the expression level of a single-chain antibody designed to be targeted to both the cytosol and the secretory pathway in transgenic tobacco. Plant Mol Biol 30:781-793

Shamloul M, Trusa J, Mett V \& Yusibov V (2014) Optimization and Utilization of Agrobacterium-mediated Transient Protein Production in Nicotiana. JoVE:e51204.

Shanmugaraj B, Christine-Joy IB, Phoolcharoen W (2020) Plant molecular farming: a viable platform for recombinant biopharmaceutical production. Plants 9:1

Szala S, Froehlich M, Scollon M, Kasai Y, Steplewski Z, Koprowski $\mathrm{H}$, Linnenbach AJ (1990) Molecular cloning of cDNA for the carcinoma-associated antigen GA733-2. Proc Natl Acad Sci USA 87:3542-3546

Takeyama N, Kiyono H, Yuki Y (2015) Plant-based vaccines for animals and humans: recent advances in technology and clinical trials. Ther Adv Vaccines 3:139-154

Tauriello DV, Calon A, Lonardo E, Batlle E (2017) Determinants of metastatic competency in colorectal cancer. Mol Oncol 11:97-119

Temraz S, Mukherji D, Shamseddine A (2014) Sequencing of treatment in metastatic colorectal cancer: where to fit the target. World J Gastroenterol 20:1993-2004

Tokmakov AA, Kurotani A, Takagi T, Toyama M, Shirouzu M, Fukami Y, Yokoyama S (2012) Multiple post-translational modifications affect heterologous protein synthesis. J Biol Chem 287:27106-27116

Tusé D, Nandi S, McDonald KA, Buyel JF (2020) The emergency response capacity of plant-based biopharmaceutical manufacturing-What it is and what it could be. Front Plant Sci 11:1
Ullrich KK, Hiss M, Rensing SA (2015) Means to optimize protein expression in transgenic plants. Curr Opin Biotechnol 32:61-67

Van Droogenbroeck B, Cao J, Stadlmann J, Altmann F, Colanesi S, Hillmer S, Robinson DG, Van Lerberge E, Terryn N, Van Montagu M, Liang M, Depicker A, Jaeger GD (2007) Aberrant localization and underglycosylation of highly accumulating single-chain $\mathrm{Fv}-\mathrm{Fc}$ antibodies in transgenic Arabidopsis seeds. Proc Natl Acad Sci U S A 104:1430-1435

Verch T, Hooper DC, Kiyatkin A, Steplewski Z, Koprowski H (2004) Immunization with a plant-produced colorectal cancer antigen. Cancer Immunol Immunother 53:92-99

Wilson IB, Zeleny R, Kolarich D, Staudacher E, Stroop CJ, Kamerling JP, Altmann F (2001) Analysis of Asn-linked glycans from vegetable foodstuffs: widespread occurrence of Lewis a, core alpha1,3linked fucose and xylose substitutions. Glycobiology 11:261-274

Wong-Arce A, González-Ortega O, Rosales-Mendoza S (2017) Plantmade vaccines in the fight against cancer. Trends Biotechnol 35:241-256

Zahin M, Joh J, Khanal S, Husk A, Mason H, Warzecha H, Ghim S-j, Miller DM, Matoba N, Jenson AB (2016) Scalable production of HPV16 L1 protein and VLPs from tobacco leaves. PLoS ONE 11:e0160995

Zost SJ, Parkhouse K, Gumina ME, Kim K, Diaz Perez S, Wilson PC, Treanor JJ, Sant AJ, Cobey S, Hensley SE (2017) Contemporary H3N2 influenza viruses have a glycosylation site that alters binding of antibodies elicited by egg-adapted vaccine strains. Proc Natl Acad Sci USA 114:12578-12583

Publisher's Note Springer Nature remains neutral with regard to jurisdictional claims in published maps and institutional affiliations. 